\title{
Determination of Gender from Various Measurements of the Humerus
}

\author{
Muhammad Amjad Khan ${ }^{1}$, Humara Gul ${ }^{2}$, Shahid Mansor Nizami ${ }^{3}$ \\ 1. Anatomy, Bakhtawar Amin Medical and Dental College, Multan, PAK 2. Anatomy, Abwa Medical College, Faisalabad, \\ PAK 3. Anatomy, Nishtar Medical University, Multan, PAK
}

Corresponding author: Muhammad Amjad Khan, dramjidbmdc@gmail.com

\section{Abstract \\ Objective}

To study different measurements of the humerus for the determination of sex

\section{Study design}

A cross-sectional study

\section{Place and duration of study}

The Anatomy Department of Nishtar Medical University and Hospital from June 1, 2018, to May 31, 2019.

\section{Methodology}

Six measurements, including maximum length of the humerus (MLH), maximum diameter of the head of the humerus $(\mathrm{MDH})$, vertical diameter of the head of the humerus $(\mathrm{VDH})$, transverse diameter of the head of the humerus (TDH), epicondylar breadth (EB), and condylar breadth (CB) were calculated for 122 male humeri and 52 female humeri. These variables were compared between both genders using the student's t-test. Wilks' lambda test was applied. The demarking point of all these variables was defined as the average of the means of male and female measurements. Correctly identified cases were calculated in the male group, the female group, and the whole study group. Data analysis was done in SPSS v.23.0 (IBM Corp, Armonk, NY). $\mathrm{P}>0.05$ was statistically insignificant.

\section{Results}

The differences of MLH, MDH, VDH, TDH, EB, and CB were statistically significant between both the genders $(\mathrm{p}<0.001)$. The accuracy of MLH was $85 \%$ in the total population. The accuracy of MDH, VDH, and TDH was $76 \%, 85 \%$, and $76 \%$ in the total population, respectively. EB and CB correctly identified $75 \%$ and $78 \%$ of all the bones.

Received 01/04/2020

Review began 01/04/2020 Review ended 01/05/2020 Published 01/08/2020

\section{(c) Copyright 2020}

Khan et al. This is an open access article distributed under the terms of the Creative Commons Attribution License CC-BY 3.0., which permits unrestricted use, distribution, and reproduction in any medium, provided the original author and source are credited.

\section{Conclusion}

This study shows that maximum humeral length and the vertical diameter of the humeral head are the two most important measurements with the highest accuracy for the determination of gender from the skeletal remains of the human body in the South-East Asian population.

\section{Categories: Anatomy}

Keywords: gender, determine, humerus, forensics, skeletal remains

\section{Introduction}

In forensic anthropology, it is very important to determine the sex from the bony remains found at an excavation site or a crime scene. The humerus is a big bone in the upper limb and its condition does not usually deteriorate, which is why the humerus is favored for the determination of sex. The length of various bones in the human body, including the humerus, is a good predictor of gender but the accuracy of the vertical diameter of the head is also significant in sex determination [1-2]. Numerous studies have been conducted on the measurements of upper limb bones including the humerus and metric systems devised in Chile [2], South Africa [3], Guatemala [4], the Dart collection [4-5], the island of Crete [1,6-7], Turkey [8], Greece [9], America [10], and the Eastern Adriatic coast [11].

Many factors are important for forensic specialists for the identification of unknown dead bodies. Estimation of body stature and determination of sex are the most important factors used to establish the identity of unidentifiable dead bodies. Determination of sex is considered an easy job, as external and internal genitalia directly point towards the gender of the individual [12]. But this task becomes a challenge when it comes to 
severely decomposed dead bodies. Determination of sex is also important in the evaluation of other parameters such as body stature [13]. The simplest method of sex determination is the visual assessment of the bone and the inspection of the bony landmarks distinctive of gender. This qualitative method is more accurate if a significant part of the skeleton is available. Another method used is the morphometric technique and is considered more accurate. This metric method depends on direct measurements between various bony points and the intricate outlines of the bones cannot be evaluated [14-15].

Upper limb bones vary in size among different populations. The length of the humerus is different in the African, American, and European populations. There are significant differences among Asian populations. The discriminant value for the length of the humerus has been calculated for various Asian populations, including Thai, Japanese, and Chinese. Sex determination has been done using the skull, mandible, pelvic bone, hyoid bone [16], corpus callosum [17], and thyroid cartilage in the Korean population [18].

Despite having low accuracy, a determination of sex can be made by the quantitative analysis of the complete bone or even fragments of bones. Although upper limb bones, including the humerus, preserve their integrity, they are usually fragmented at the time of retrieval. This study is directed to derive demarking values for the whole humerus or fragments of the humerus in the south Asian population. The aim of this study is to devise accurate anthropometric standards to determine the sex from different measurements of the humerus. As in our region, this subject remained of least priority; this study will help fill this gap and open new gates of research on this topic.

\section{Materials And Methods}

This cross-sectional study was conducted on 174 humeri, which included 122 humeri from male cadavers and 52 humeri from female cadavers. The duration of the study was one year, i.e. from June 1, 2018, to May 31, 2019. The sample size was calculated [19] and the nonprobability consecutive sampling technique was used to select the bones for the study. The study was approved by the review board of Nishtar Medical University and Hospital. All the humeri were removed from the cadavers of adult individuals of estimated age between 25 years and 75 years in the anatomy department. All the bones were examined for any obvious deformity. Bones indicating obvious deformities, including healed fractures, neoplastic bone disease, and developmental defects, were excluded.

All the bones were cleaned after removal from the cadavers. A surgical knife was used to remove the articulate cartilages. An osteometric table, measuring tape, and digital calipers were the instruments of choice for various measurements of the humeri. Six humerus measurements were included, i.e. maximum length of the humerus (MLH), maximum diameter of the head of the humerus (MDH), vertical diameter of the head of the humerus (VDH), transverse diameter of the head of the humerus (TDH), condylar breadth (CB), and epicondylar breadth (EB). The maximum humerus length was defined as the displacement between the top-most projection of the humeral head to the lowest point on the trochlea. VDH was the displacement between the highest and lowest points on the margin of the articular surface of the humeral head. The transverse diameter of the head was the displacement between the most anterior and most posterior points on the margin of the articular surface of the humeral head. Epicondylar breadth was the distance of the two most laterally projecting points on the lateral epicondyles of the humerus.

All these six variables, MLH, MDH, VDH, TDH, EB, and CB, were compared between both genders using the student's t-test. Wilks' lambda test was applied for all these measurements. The demarking point of all these variables was defined as the average of the means of male and female measurements. Correctly identified cases were calculated in the male group, female group, and the whole study group. Data analysis was done in SPSS v.23.0 (IBM Corp, Armonk, NY). P>0.05 was statistically insignificant.

\section{Results}

The mean maximum length of the humerus was $304.56 \pm 14.16 \mathrm{~mm}$ and $276.60 \pm 10.89 \mathrm{~mm}$ in males and females, respectively $(\mathrm{p}<0.001)$. The maximum diameter, vertical diameter, and transverse diameter of the humeral head were $44.95 \pm 1.72 \mathrm{~mm}, 44.73 \pm 1.70 \mathrm{~mm}$, and $40.92 \pm 1.71 \mathrm{~mm}$ in the males while $41.34 \pm 2.07$ $\mathrm{mm}, 40.98 \pm 1.72 \mathrm{~mm}$, and $38.36 \pm 1.69 \mathrm{~mm}$ in the females, respectively $(\mathrm{p}<0.001)$. Epicondylar breadth was $59.44 \pm 3.20 \mathrm{~mm}$ in the males and $54.52 \pm 2.30 \mathrm{~mm}$ in the females $(\mathrm{p}<0.001)$. Condylar breadth was $41.23 \pm$ $1.91 \mathrm{~mm}$ and $38.73 \pm 1.76 \mathrm{~mm}$ in the males and females, respectively $(\mathrm{p}<0.001)$. See Table 1 . 


\section{Cureus}

\begin{tabular}{|c|c|c|c|}
\hline Variable & Male $(n=122)$ & Female $(n=52)$ & p-value \\
\hline $\mathrm{MLH}, \mathrm{mm}$ & $304.56 \pm 14.16$ & $276.60 \pm 10.89$ & $<0.001$ \\
\hline $\mathrm{MDH}, \mathrm{mm}$ & $44.95 \pm 1.72$ & $41.34 \pm 2.07$ & $<0.001$ \\
\hline VDH, mm & $44.73 \pm 1.70$ & $40.98 \pm 1.72$ & $<0.001$ \\
\hline TDH, mm & $40.92 \pm 1.71$ & $38.36 \pm 1.69$ & $<0.001$ \\
\hline $\mathrm{EB}, \mathrm{mm}$ & $59.44 \pm 3.20$ & $54.52 \pm 2.30$ & $<0.001$ \\
\hline $\mathrm{CB}, \mathrm{mm}$ & $41.23 \pm 1.91$ & $38.73 \pm 1.76$ & $<0.001$ \\
\hline
\end{tabular}

\section{TABLE 1: Variable comparison between two genders}

Table 2 represents the discriminant function coefficient of all the bony measurements separating males from females. A measured value less than the demarking point was labeled as female and a measured value greater than the demarking point was labeled as male. For example, a value above $290.5 \mathrm{~mm}$ for the maximum length of the humerus will be considered male whereas a value less than $290.5 \mathrm{~mm}$ will be considered female. The demarking points for MDH, VDH, TDH, EB, and CB are $43.1 \mathrm{~mm}, 42.8 \mathrm{~mm}, 39.6 \mathrm{~mm}$, $56.9 \mathrm{~mm}$, and $39.9 \mathrm{~mm}$, respectively.

\begin{tabular}{|c|c|c|c|}
\hline Variable & Demarking point & Wilks' lambda & $p$-value \\
\hline MLH & $F<290.5$ & 0.516 & $<0.001$ \\
\hline MDH & $\mathrm{F}<43.1$ & 0.548 & $<0.001$ \\
\hline VDH & $F<42.8$ & 0.494 & $<0.001$ \\
\hline TDH & $F<39.6$ & 0.676 & $<0.001$ \\
\hline EB & $\mathrm{F}<56.9$ & 0.631 & $<0.001$ \\
\hline CB & $F<39.9$ & 0.725 & $<0.001$ \\
\hline
\end{tabular}

TABLE 2: Demarking point for males and females

The accuracy of measurements of the humerus in determining sex is represented in Table 3 . The accuracy of MLH was $81 \%$ in males, $94 \%$ in females, and $85 \%$ in the total population. The accuracy of MDH, VDH, and TDH was $69 \%$, $90 \%$, and $75 \%$ in males; $92 \%, 75 \%$, and $77 \%$ in females; and $76 \%, 85 \%$, and $76 \%$ in the total population, respectively. $\mathrm{EB}$ and $\mathrm{CB}$ correctly identified $78 \%$ and $81 \%$ of male bones, $67 \%$ and $71 \%$ of female bones, and $75 \%$ and $78 \%$ of all bones.

\begin{tabular}{|c|c|c|c|}
\hline Variable & Male & Female & Average \\
\hline MLH & $81 \%$ & $94 \%$ & $85 \%$ \\
\hline MDH & $69 \%$ & $92 \%$ & $76 \%$ \\
\hline $\mathrm{VDH}$ & $90 \%$ & $75 \%$ & $85 \%$ \\
\hline TDH & $75 \%$ & $77 \%$ & $76 \%$ \\
\hline$E B$ & $78 \%$ & $67 \%$ & $75 \%$ \\
\hline CB & $81 \%$ & $71 \%$ & $78 \%$ \\
\hline
\end{tabular}

TABLE 3: Percentage of correctly classified cases 


\section{Discussion}

Measurements of long bones have significant medico-legal importance in the identification of missing persons. The humerus is the chief bone of the upper limb and it maintains its integrity long after the body has decomposed. The length of the humerus has been reported to be important in the identification of specific features of the population [20]. In our study, the average length of the humerus was $304.56 \pm 14.16$ $\mathrm{mm}$ and $276.60 \pm 10.89 \mathrm{~mm}$ in males and females, respectively. In Brazil, a study was conducted and it found the average humerus length to be $31.3 \pm 2.3$ [21] cm while MLH was found to be $30.28 \pm 2.44 \mathrm{~cm}$ in a study conducted in southern India [22]. A profound difference was observed by Devi et al. [23] between the length of the right and left humerus of the same body with the average right-sided length being $30.84 \pm 1.78 \mathrm{~cm}$. MLH was $30.78 \pm 1.57 \mathrm{~cm}$ in a study conducted on the northern Thai population [24].

Segmental measurements of the humerus can be used to estimate the length of the humerus. Gayatri et al. [25] observed a significant relationship of epicondylar breadth and the vertical diameter of the head of the humerus with the maximum length of the humerus. Similar results were observed in the study conducted by Udhaya et al. [22]. A significant relationship of segmental measurements with the length of the humerus was also observed by Salles et al. [26].

For a forensic expert, the determination of gender is the first step in the identification of an unknown person. It is common practice to use a discriminant function equation to determine gender from the skeletal remains of the individual. But it has been understood that these equations are population specific. This has made it compulsory to develop separate equations for every regional population [27]. We observed in our study that there is a noteworthy difference in all humeral measurements between the male and female groups, which shows sexual dimorphism in all the segmental measurements of the humerus in the SouthEast Asian population. The discriminant functions derived in our study will be of substantial help for medico-legal specialists in the region.

In our study, we observed that maximum humeral length and VDH are good dimensions for the differentiation of sex with correct sexual differentiation being $85 \%$. Lee et al. [19] publicized that VDH had the highest accuracy for the differentiation of sex. Patil et al. [28] conducted a study in southern India and observed that the length of the humerus and the mid-shaft diameter of the humerus are good measurements for gender identification.

The single finest factor for gender determination was epicondylar breadth (with $87.5 \%$ accuracy) and was observed by Soni et al. [29] while vertical diameter was the best parameter in another study [7]. These differences in measurement are expected to be dependent on the difference in the body size, muscle mass, and physical activity, significantly more development of the cortical bone in adolescent males than in females, and differences in bone remodeling between both genders [30].

\section{Conclusions}

This study shows that the maximum humeral length and the vertical diameter of the humeral head are the two most important measurements with the highest accuracy for the determination of gender from the skeletal remains of the human body in the South-East Asian population.

\section{Additional Information \\ Disclosures}

Human subjects: All authors have confirmed that this study did not involve human participants or tissue. Animal subjects: All authors have confirmed that this study did not involve animal subjects or tissue. Conflicts of interest: In compliance with the ICMJE uniform disclosure form, all authors declare the following: Payment/services info: All authors have declared that no financial support was received from any organization for the submitted work. Financial relationships: All authors have declared that they have no financial relationships at present or within the previous three years with any organizations that might have an interest in the submitted work. Other relationships: All authors have declared that there are no other relationships or activities that could appear to have influenced the submitted work.

\section{References}

1. Kranioti EF, Bastir M, Sánchez-Meseguer A, Rosas A: A geometric-morphometric study of the Cretan humerus for sex identification. Forensic Sci Int. 2009, 111:1-8. 10.1016/j.forsciint.2009.04.013

2. Ross AH, Manneschi MJ: New identification criteria for the Chilean population: estimation of sex and stature. Forensic Sci Int. 2011, 204:206. 10.1016/j.forsciint.2010.07.028

3. Vance VL, Steyn M, L’Abbé EN: Nonmetric sex determination from the distal and posterior humerus in black and white South Africans. J Forensic Sci. 2011, 56:710-714. 10.1111/i.1556-4029.2011.01724.X

4. Frutos LR: Metric determination of sex from the humerus in a Guatemalan forensic sample . Forensic Sci Int. 2005, 147:153-7. 10.1016/j.forsciint.2004.09.077

5. Barrier IL, L'Abbé EN: Sex determination from the radius and ulna in a modern South African sample . Forensic Sci Int. 2008, 179:85. 10.1016/j.forsciint.2008.04.012 
6. Kranioti EF, Nathena D, Michalodimitrakis M: Sex estimation of the Cretan humerus: a digital radiometric study. Int J Leg Med. 2011, 125:659-667. 10.1007/s00414-010-0470-4

7. Kranioti EF, Michalodimitrakis M: Sexual dimorphism of the humerus in contemporary Cretans-a population-specific study and a review of the literature. J Forensic Sci. 2009, 54:996-1000. 10.1111/j.15564029.2009.01103.x

8. Üzün I, Iscan MY, Çelbis O: Forearm bones and sexual variation in Turkish population . Am J Forensic Med Pathol. 2011, 32:355-358. 10.1097/PAF.0b013e318219ca74

9. Charisi D, Eliopoulos C, Vanna V, Koilias CG, Manolis SK: Sexual dimorphism of the arm bones in a modern Greek population. J Forensic Sci. 2011, 56:10-18. 10.1111/j.1556-4029.2010.01538.x

10. Milner GR, Boldsen JL: Humeral and femoral head diameters in recent white American skeletons . J Forensic Sci. 2012, 57:35-40.

11. Bašić Ž, Anterić I, Vilović K, Petaros A, Bosnar A, Madžar T: Sex determination in skeletal remains from the medieval Eastern Adriatic coast-discriminant function analysis of humeri. Croatian Med J. 2013, 54:272-278. 10.3325/cmj.2013.54.272

12. Kanchan T, Krishan K: Anthropometry of hand in sex determination of dismembered remains - a review of literature. J Forensic Leg Med. 2011, 18:14-7.

13. Hemy N, Flavel A, Ishak NI, Franklin D: Sex estimation using anthropometry of feet and footprints in a Western Australian population. Forensic Sci Int. 2013, 231:402. 10.1016/j.forsciint.2013.05.029

14. Vacca E, Di Vella G: Metric characterization of the human coxal bone on a recent Italian sample and multivariate discriminant analysis to determine sex. Forensic Sci Int. 2012, 222:401. 10.1016/j.forsciint.2012.06.014

15. Kanabur V: Identification of the sex of human hip bone by metric analysis of its anterior border . Biomed Res. 2012, 23:211-214.

16. Kim DI, Lee UY, Park DK, Kim YS, Han KH, Kim KH: Morphometrics of the hyoid bone for human sex determination from digital photographs. J Forensic Sci. 2006, 51:979-984. 10.1111/j.1556-4029.2006.00223.x

17. Rhyu IJ, Ryu JY, Park KW, Lee DH, Park KY, Park KH: Gender difference on corpus callosum in Korean adults. Korean J Phys Anthropol. 2005, 18:169-177. 10.11637/kjpa.2005.18.3.169

18. Park DK, Kim DI, Lee UY, Han KH, Kim KH, Han SH: Morphometric analysis of the Korean thyroid cartilage for identification of sex: metric study. Korean J Phys Anthropol. 2003, 16:129-136. 10.11637/kjpa.2003.16.3.129

19. Lee JH, Kim YS, Lee U, Park DK, Jeong YG, Lee NS: Sex determination using upper limb bones in Korean populations. Anat Cell Biol. 2014, 47:196-201. 10.5115/acb.2014.47.3.196

20. Wright LE, Vásquez MA: Estimating the length of incomplete long bones: forensic standards from Guatemala. Am J Phys Anthropol. 2003, 120:233-251. 10.1002/ajpa.10119

21. Salles AD, Carvalho CR, Silva DM, Santana LA: Reconstruction of humeral length from measurements of its proximal and distal fragments. Braz J Morphol Sci. 2009, 26:55-61.

22. Udhaya K, Sarala Devi KV, Sridhar J: Regression equation for estimation of length of humerus from its segments: a South Indian population study. J Clin Diag Res. 2011, 5:783-786.

23. Devi R, Thakar MK, Nath S: Estimation of humeral length from its fragmentary dimensions . Hum Biol Rev. 2014, 3:15-24.

24. Mahakkanukrauh P, Khanpetch P, Prasitwattanseree S, Vichairat K, Case DT: Stature estimation from long bone lengths in a Thai population. Forensic Sci Int. 2011, 210:279. 10.1016/j.forsciint.2011.04.025

25. Gayatri, Kamdi A, Shark A, Krishnaiah M, Sharada HR: Estimation of humerus length from its segments in Telangana state. J Dent Med Sci. 2014, 13:18-21. 10.9790/0853-13941821

26. Salles AD, Carvalho CR, Silva DM, Santana LA: Reconstruction of humeral length from measurements of its proximal and distal fragments. Braz J Morphol Sci. 2009, 26:55-61.

27. Bidmos MA, Dayal MR: Further evidence to show population specificity of discriminant function equations for sex determination using the talus of South African blacks. J Forensic Sci. 2004, 49:1165-1170. 10.1520/JFS2003431

28. Patil G, Kolagi S, Ramadurg U: Sexual dimorphism in the humerus: a study on South Indians . J Clin Diagn Res. 2011, 5:538-541.

29. Soni G, Dhall U, Chhabra S: Determination of sex from humerus: discriminant analysis . Australian J Forensic Sci. 2013, 45:147-152. 10.1080/00450618.2012.697917

30. Bašić Ž, Anterić I, Vilović K, et al.: Sex determination in skeletal remains from the medieval Eastern Adriatic coast - discriminant function analysis of humeri. Croatian Med J. 2013, 54:272-278. 10.3325/cmj.2013.54.272 